\title{
Estimation of Vitamin D Levels in Women with Carpal Tunnel Syndrome (with and without Diabetes)
}

\author{
Ghadeer hamid AL-Ardhi ${ }^{1}$, Adil Mohammed AL-Maamory ${ }^{1}$, Ali Mohammed Abd- Alameer ${ }^{1}$ \\ ${ }^{1}$ Assist. Lecturer, Department of biology, DNA Research center, University of Babylon, Al- Hila, Iraq
}

\begin{abstract}
Objective: Vitamin D is a an important vitamin which is effect on several system of human body, in this study we determination serum levels of vitamin D in women patients with carpal tunnel syndrome (CTS) and investigation the relation between vitamin $\mathrm{D}$ and diabetes on CTS patients.

Materials and Method: Subjects of this study enrolled 53 women (33 patients and 20 control), their aged range between (30-50) year. The patients were selected from attendee of out- patient Neurology clinic of Al- Imam Sadiq teaching Hospital, Hilla city, Iraq, in the period from December 2018 to April 2019. Blood samples were taken from subject to determination vitamin D levels.
\end{abstract}

Results: The present study shows a significant $(\mathrm{p}<0.05)$ decrease in the mean of vitamin $\mathrm{D}$ level in women patients with CTS comparison with control women $(15.6 \pm 10.2),(32.7 \pm 16.7)$ respectively. No significant difference was found between vitamin $\mathrm{D}$ and diabetes regarding the CTS.

Conclusion: The role of vitamin D is the one potential cause of CTS, this study revealed low serum vitamin D level in patient with CTS compared to control .

Keywords: vitamin D, carpal tunnel syndrome, diabetes.

\section{Introduction}

Vitamin D (1,25- dihydroxyvitamin D3) is an extremely important vitamin that has powerful effects on several systems throughout the body ${ }^{1}$. It is a fat soluble vitamin stored in the body tissues and it is the only vitamin that can be synthesized by the human body from the cholecalciferon in the skin from the cholesterol through a chemical reactions when exposed to sunlight, especially the ultraviolet $\mathrm{B}$ radiation (UVB) ${ }^{2}$, and also its found in certain food such as fatty fish and fortified dairy products, though it's very difficult to get enough from diet alone ${ }^{3}$. Vitamin D should be considered for immune system, cell growth, protein synthesis, muscle function ${ }^{4,5}$ and musculoskeletal pains ${ }^{6}$. Receptors of vitamin $\mathrm{D}$ is found in bone, kidney, gonads, pancreas, breast, cardiovascular system, brain and immune cells such as macrophages and lymphocytes B and T and monocytes, all these target tissues can convert 25-hydroxy vitamin $\mathrm{D}$ to 1,25 - dihydroxyvitamin $\mathrm{D}^{\mathbf{7 , 8}}$. Vitamin $\mathrm{D}$ deficiency in adults is a common problem worldwide(9), low level of this hormone related to neuropathy in patients with diabetes and other neurodegenerative disorders 10. Also, it has been reported to play a potential role in non-specific persistent painful conditions ${ }^{11}$, on the other hand, many researches suggests that vitamin D could play a role in prevention and treatment of many different conditions, including type 1 and type 2 diabetes, hypertension, glucose intolerance, and multiple sclerosis ${ }^{\mathbf{1 1}}$. Carpal tunnel syndrome (CTS) is a medical condition due to compression of the median nerve as it travels through the wrist at the carpal tunnel 12. It is more common in women and usually begins in adulthood its causes pain, numbness, dysesthesia and loss of strength in hands ${ }^{\mathbf{1 3}}$. The etiological factors of CTS is systemic diseases, such as diabetes mellitus, thyroid function disorders, rheumatoid arthritis, and the most common risk factors for the development of its pregnancy, obesity and recurrent wrist movements 14,15. The CTS occurs due to increased pressure in the carpal tunnel on the median nerve inducing marked changes in intraneural microcirculation and nerve fiber 
structure, impairment of axonal transport, and alterations in vascular permeability, with edema formation and deterioration of nerve function ${ }^{\mathbf{1 6}}$. This study was aimed to investigate the effect of vitamin $\mathrm{D}$ on the patients with CTS and comparison with control and examine if a possible association could be found between vitamin D and diabetes in CTS patient.

\section{Subjects and Method}

The current study included 53 subjects (33 patients and 20 control), their aged range between (30-50) year. The patients were selected from attendee of out- patient Neurology clinic of Al- Imam Sadiq teaching Hospital, Hilla city, Iraq, in the period from December 2018 to April 2019. We included patients with diagnosis of CTS based on both clinical symptoms and positive neurophysiology, then taken $5 \mathrm{ml}$ venous blood to determination vitamin D levels. The control group included 20 volunteer with negative neurophysiology and also taken $5 \mathrm{ml}$ venous blood to measuring vitamin D level. Each group of (patients and control) were divided into two groups with and without diabetes. Serum level of vitamin D was determined by Enzyme Linked Fluorescent Assay
(ELFA). A questionnaire was designed to collect data including: age, chronic diseases, drug history, smoking, quality of life and type of work. Serum levels less than $20 \mathrm{ng} / \mathrm{ml}$ are considered as deficiency, 20 to $30 \mathrm{ng} / \mathrm{ml}$ insufficient, and over $30 \mathrm{ng} / \mathrm{ml}$ are sufficient amount of vitamin $\mathrm{D}^{17}$.

\section{Statistical Analysis}

Data were analyzed with SPSS software version 25, Independent T- Test used to calculate mean and SD for vitamin D levels and age between case and control groups and the relation between vitamin $\mathrm{D}$ and diabetes were tested by Chi- square test.

\section{Results}

Data of the current study show a low significant differences at $(p>0.05)$ of vitamin $D$ levels in patient with CTS comparison with control (15.7 \pm 10.2$),(32.7 \pm$ 16.7) respectively. As well, there was no significant difference in mean age of patients and control women $(43.8 \pm 6.7),(41.6 \pm 6.03)$ respectively as show in table 1 .

Table 1. Average vitamin D levels and age of control and case groups.

\begin{tabular}{|llll|}
\hline & Parameters & Mean \pm SD & P- Value \\
\cline { 2 - 3 } & Control & Case & 0.002 \\
& $(\mathbf{n}=\mathbf{2 0})$ & $(\mathbf{n}=\mathbf{3 3})$ & \\
\hline Vitamin D & $\mathbf{3 2 . 7} \pm \mathbf{1 6 . 7}$ & $\mathbf{1 5 . 7} \pm \mathbf{1 0 . 2}$ \\
\hline Age & $\mathbf{4 1 . 6} \pm \mathbf{6 . 0 3}$ & $\mathbf{4 3 . 8} \pm \mathbf{6 . 7}$ \\
\hline
\end{tabular}

- Significant at 0.05 level.

On the other hand, there was no significant association in normal and CTS group between vitamin D and diabetes in this study as shown in the figure 1 . 


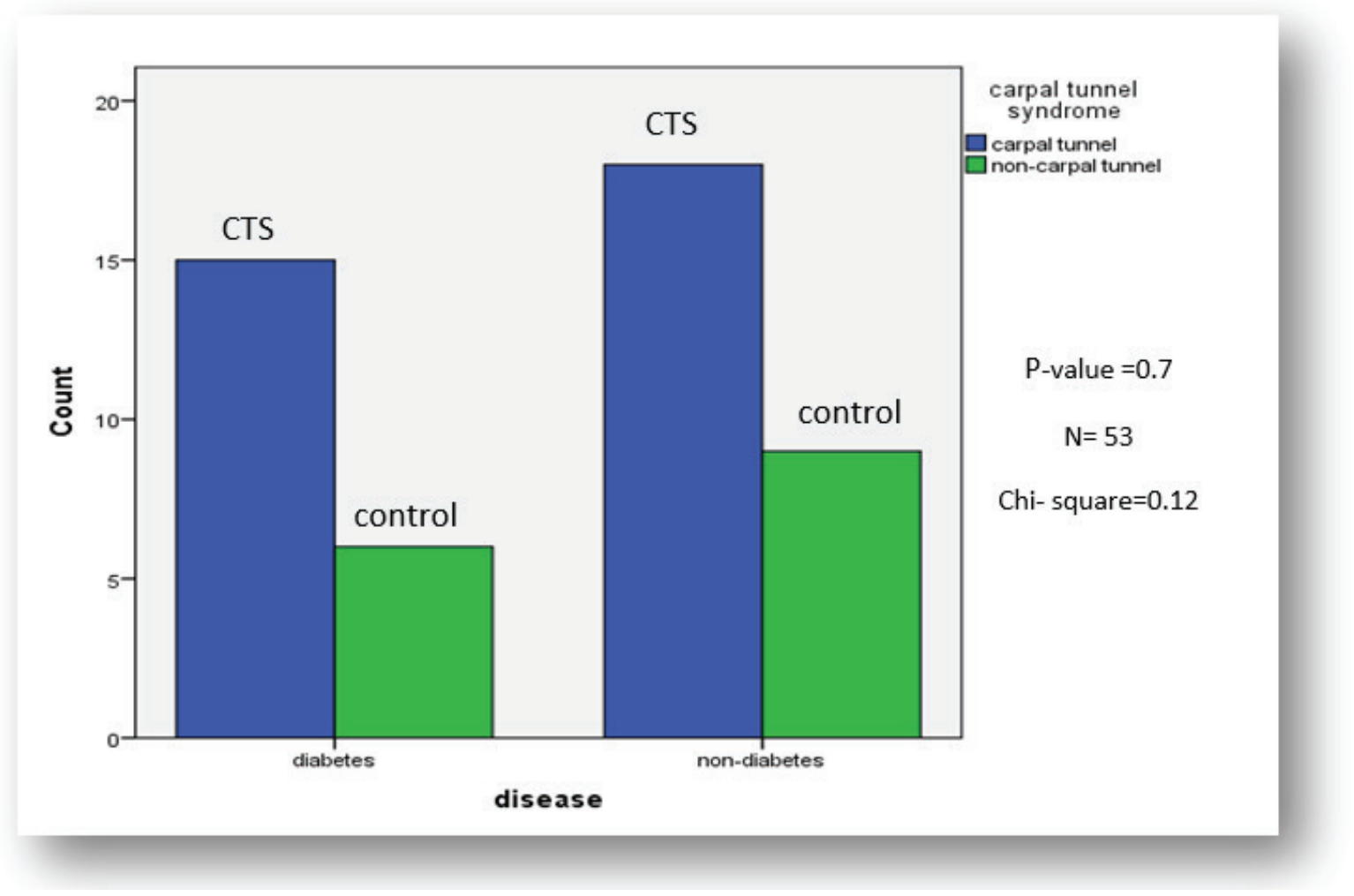

Figure 1. vitamin D level in control and CTS patients with and without diabetes.

\section{Discussions}

For decades, the role of vitamin D was recognized as calcium and phosphate homeostasis, the growing evidence suggesting that the role of vitamin D effected on other target organs especially peripheral nervous $\operatorname{system}(18)$.

The data of present study showed that CTS patients had a significantly low vitamin D levels than control. This observation was in agreement with recent study that was found the CTS may be triggered by vitamin D deficiency, and that the severity of CTS was correlated with vitamin D levels in the deficiency group $(19,20)$.

Vitamin D is considered as a neuroactive steroid, it was recorded previously that vitamin $\mathrm{D}$ induces nerve growth factor and hence could help in the prevention of neurotrophic deficits(21). Furthermore, vitamin D influences the myelination through the activation of several myelin- associated genes as demonstrated by Chabas 2013(22). In addition, data from animal studies showed that vitamin D deficiency was associated with induced nerve condition abnormalities. Acceptable with these results, animal data and basic research studies demonstrated that vitamin $D$ receptors exist on peripheral nerves and Schwann cells, and consequently, vitamin D could promote production of nerve growth factor and axon regeneration in peripheral nerves $(23,24)$. Notable effect of vitamin D in reducing musculoskeletal pain and numbness, therefore, vitamin D may be used as improvement and treatment of CTS patients(25).

The previous studies which were conducted on a group of patients with diabetic neuropathy showed a relevant association between vitamin $\mathrm{D}$ and the development of diabetic neuropathy

Atherton et al 2009 found vitamin D levels related to chronic widesgread pain ${ }^{26}$. Similarly, Knutsenet al 2010, notice a higher prevalence of hypovitamin D among those with nonspecific musculoskeltal pain, fatigue, or headache ${ }^{17}$. As for, the results of this study refers there is no significant association in normal and CTS group between vitamin D and diabetes and this disagreement with several studies which is suggested there is an association between diabetic neuropathic pain, diabetic neuropathy and vitamin D levels ${ }^{\mathbf{2 8 , 2 9}}$, the 
small samples size did not give a clear indication. also we can explain this case for a low level of vitamin D is tightly related with CTS in both groups (with and without diabetes) as Moon et al 2015 explained low vitamin D is related to neuropathy in patients with diabetes and other neurodegenerative disorders (10). On the other hand, we can expect the nature of work and stress may trigger symptoms of CTS by sever and recurrent use of hand, we found most young women without diabetes and suffering from CTS this may be related to the nature of domestic work, especially housewives and this agreement with Swanson et al 2013(30), as for women with diabetes and CTS, diabetes may have contributed to the development of CTS and possibly genetics or another factors ${ }^{31}$.

Financial Disclosure: There is no financial disclosure.

Conflict of Interest: None to declare.

Ethical Clearance: All experimental protocols were approved under the Department of biology and all experiments were carried out in accordance with approved guidelines.

\section{References}

1. Aranow A. Vitamin D and Immune system. J Investing Med. 2012; 59(6): 881-886.

2. Mac Donald J. How does the body make vitamin D from sunlight. 2019

3. Betty Y, Faisal A, Hadi R, Nur E. Food sources of vitamin $\mathrm{D}$ and its deficiency in worker women. International Conference (AASIC). 2016; 20: 233239

4. Ceglia L. vitamin D and skeletal muscle tissue and function. Molecular Aspects of Medicine. 2008; 29(6): 407- 14

5. Willis KS, Smith DT, Broughton KS, LarsonMeyer DE. Vitamin D status and biomarkers of inflammation in runners. Open Access Journal of sports Medicine. 2012; 3(2): 35:42.

6. Plotnikoff GA, Quigley JM. Prevalence of severe hypovitaminosis $\mathrm{D}$ in patients with persistent, nonspecific musculoskeletal pain. In Mayo clinic proceedings. Elsevier. 2003; 78(12): 1463- 1470.

7. Shehab D, Al- Jarallah K, Mojiminiy OA, AlMohamedy H, Abdella NA. does vitamin D deficiency play a role in peripheral neuropathy in type 2 diabetes? Diabetic Medicin. 2012; 29(1): 4349.

8. Bell DSH. Reversal of the symptoms of diabetic neuropathy through correction of vitamin D deficiency in type 1 diabetic patient. Case Reports in endocrinology . 2012.

9. Vierucci F, Del Pistoia M, Fanos M, Erba P, Saggese G. Prevalence of hypovitaminosis D and predictors of vitamin D status in Italian healthy adolescents. Ital J pediatr. 2014; 40:54.

10. Moon JH, Lim S, Han JW, Kim KM, Choi SH, Kim KW. serum 25-hydroxyvitamin D LEVEL and the risk of mild cognitive impairment and dementia: the Korean Longitudinal Study on Health and Aging (KLoSHA). Clin Endocrinol. 2015; 83: 36- 42.

11. Kuru P, Akyuz G, Yagci I, Giray E. Hypovitaminosis $\mathrm{D}$ in widespread pain: its effect on pain perception, quality of life and nerve condition studies. Rheumatol INT. 2015;35:315-22.

12. Burton C, Chesterton LS, Davenport G. Diagnosing and managing carpal tunnel syndrome in primary care. The British Journal of general Practice. 2014; 64(622) : 262-3.

13. B.E. Demiryurek AA. The effect of vitamin D levels on pain in carpal tunnel syndrome orthopaedics and Traumatology surgery and research. 2017; 103(919- 922).

14. Kouyourndjian JA, Zanetta DM, Motita MP. Evaluation of age, body mass index and wrist index as risk factors for carpal tunnel syndrome severity. Muscle nerve 2002; 25: 39-7.

15. Bland JDP. Do nerve conduction studes predict the outcome of carpal tunnel decompression? Muscle Nerve 2001; 24: 935- 40.

16. Abnoonq MS. Pathophysiology of carpal tunnel syndrome. Neurosciences. 2015; 20(1): 4-9.

17. Ozkan B, Hatun S, Bereket A. Vitamin D intoxication. Turk J Pediatr. 2012; 54: 93-8.

18. Shehab D, Al-Jarallah K, Mojiminiyi OA, Al Mohamedy H, Abdella NA. Does vitamin D deficiency play a role in peripheral neuropathy in type 2 diabetes? Diabet Med. 2012; 29:43-9.

19. Tanik N, Balbaloglu O, Ucar M, Sarp U, Atalay T, Celikbilek A. Does vitamin D deficiency trigger carpal tunnel syndrome? J Back Musculoskelet Rehabil. 2016; 29(4):835-9.

20. Gursoy AE, Bilgen HR, Duruyen H, Altintas O, 
Kolukisa M, Asil T. the evaluation of vitamin D levels in patients with carpal tunnel syndrome. Neurol Sci. 2016; 37:1055-61.

21. Riaz S, Malcangio M, Miller M, Tomlinson DR. Avitamin D3 derivative(CB1093) induces nerve growth factor and prevents neurotrophic deficitis in streptozotocin- diabetic rats. Diabetologia. 1999; 42:1308-13.

22. Chabas JF, Stephan D, Marqueste T. Cholecalciferol (vitamin D3) improves myelination and recovery after nerve injury. PLoS One. 2013; 8:e65034.

23. Cornet A, Baudet C, Neveu I, Baron-Van Evercooren A, Brachet P, Naveilhan P. 1,25Dihydroxyvitamin D3 regulates the expression of VDR and NGF gen in Schwan cells in vitro. J Neurosci Res. 1998; 53:742-6.

24. Chabas JF, Alluin O, Rao G. Vitamin D2 protentiates axon regeneration. J Neuro- Oncol. 2008; 25: 1247-56.

25. Seyed M, Sharareh R, Marzieh M. Investigation of serum levels of Vitamin D in patients with intractable carpal tunnel syndrome referred to physical medicine and rehabilitation clinics of Shiraz university of medical sciences in 2015. World family medicin. 2018; 16(3): 232-235.
26. Atherton K, Berry DJ, Parsons T, Macfarlane GJ, Power C, Hyppo nen E. Vitamin D and chronic widespread pain in a white middle- aged British population: evidence from a cross- sectional population survey. Ann Rheum Dis. 2009; 68(6): 817-22.

27. Knutsen KV, Brekke M, Gjelstad S, Lagelov P. Vitamin D status in patients with musculoskeletal pain, fatigue and headache: a cross- sectional descriptive study in a multi- ethnic general practice in Norway. Scand J Prim Health Care. 2010; 28(3): 166-71.

28. Putz Z, Martos T, Nemeth N. Is there an association between diabetic neuropathy and low vitamin $\mathrm{D}$ levels? Curr Diab Rep. 2014;14(10): 537.

29. Alamdari A, Mozafari R, Tafakhori A. An inverse association between serum vitamin $D$ levels with the presence and severity of impaired nerve conduction velocity and large fiber peripheral neuropathy in diabetic subjects. Neurol Sci. 2015; 36(7): 1121-6.

30. Swanson N. Women's health at work. The Disaste recover Journal. 2013.

31. Lozanocalderon S, Paiva A, Ring D. The quality and strength of evidence for etiology journal of hand surgery. 2008; 525-538. 